\title{
Resveratrol and fish oil reduce catecholamine-induced mortality in obese rats: role of oxidative stress in the myocardium and aorta
}

\author{
Pricila R. M. Ávila, Scherolin O. Marques, Thais F. Luciano, Marcelo F. Vitto, Julia Engelmann, \\ Daniela R. Souza, Sane V. Pereira, Ricardo A. Pinho, Fabio S. Lira and Claudio T. De Souza* \\ Laboratory of Exercise Biochemistry and Physiology, Health Sciences Unit, Universidade do Extremo Sul Catarinense, \\ 88806-000 Criciúma, SC, Brazil
}

(Submitted 16 March 2012 - Final revision received 28 January 2013 - Accepted 28 January 2013 - First published online 4 April 2013 )

\begin{abstract}
The exact mechanisms of the relationship between obesity and cardiovascular events are not yet fully understood; however, oxidative stress may be involved. Thus, the aim of the present study was to evaluate the effects of resveratrol and fish oil on catecholamine-induced mortality in obese rats. To begin with, rats were divided into five groups: (1) lean, (2) obese, (3) obese supplemented with resveratrol, (4) obese supplemented with fish oil and (5) obese supplemented with resveratrol and fish oil ( $n 18$ rats per group), for 2 months. After supplementation, the groups were subdivided as with $(n$ 10) and without $(n$ 8) cardiovascular catecholaminergic stress after isoproterenol $(60 \mathrm{mg} / \mathrm{kg})$ injection. At $24 \mathrm{~h}$ later, the survival rate was analysed. The obese group showed lower survival rates (10\%) when compared with the lean group (70\%). On the other hand, resveratrol $(50 \%)$ and fish oil (40\%) increased the survival rate of obese rats $\left(\chi^{2}\right.$ test, $P=0.019)$. Biochemical analyses of the myocardium and aorta revealed that obese rats had higher levels of superoxide and oxidative damage to lipids and protein. This was associated with reduced superoxide dismutase and glutathione peroxidase activity in both the myocardium and aorta. The supplementation increased antioxidant enzyme activities and reduced oxidative damage. We also evaluated the nuclear factor-erythroid 2 p45-related factor 2 (Nrf2)/Kelch-like ECH-associated protein 1 antioxidant pathway. Nrf2 protein levels that were reduced in obese rats were increased by the antioxidant treatment. Taken together, these results showed that resveratrol and fish oil reduce catecholamine-induced mortality in obese rats, partly through the reduction of oxidative stress.
\end{abstract}

Key words: Obesity: Mortality: Catecholamine-induced cardiovascular stress: Oxidative stress: Antioxidant nutrients

Obesity has become a problem that is fast reaching epidemic proportions worldwide ${ }^{(1)}$ and is associated with an increased risk of premature death ${ }^{(2)}$. Individuals with a central deposition of adipose tissue can experience elevated cardiovascular morbidity and mortality ${ }^{(3,4)}$. Although certain proportions of cardiovascular disorders are attributable to secondary obesity complications (hypertension, atherosclerosis and type 2 diabetes), a direct deleterious effect of obesity on the cardiovascular system is becoming more evident, including alterations in the redox state causing oxidative stress in obese patients ${ }^{(5)}$. Over the past few years, the evidence of obesity-induced oxidative stress in humans is growing (for a review, see Vincent \& Taylor $\left.{ }^{(5)}\right)$. Human studies addressing obesity and oxidative stress ${ }^{(6)}$ have found higher basal levels of malonaldehyde in lipoprotein samples and basal plasma thiobarbituric acid-reactive species (TBARS) in obese patients.
Reactive oxygen species (ROS) are unstable and highly reactive molecules that tend to initiate irreversible chemical changes in lipids or proteins. These potentially deleterious reactions can result in profound cellular dysfunction and even cytotoxicity in several tissues, including the myocardium and aorta. Endogenous enzymatic free radical scavengers, such as superoxide dismutase (SOD), glutathione peroxidase (GPx) and catalase (CAT), are efficient in detoxifying ROS. However, under such conditions as obesity that is associated with excess production of ROS, the capacity of an endogenous oxidative defence mechanism to detoxify ROS becomes limited and results in increased deleterious radical-mediated reactions ${ }^{(5)}$. In addition to endogenous enzymatic free radical scavengers, a sophisticated antioxidant pathway (nuclear factor-erythroid 2 p45-related factor 2 (Nrf2)/Kelch-like ECH-associated protein 1 (Keap1)) is existent. Under normal conditions, Keap1 anchors the Nrf2 transcription factor

\footnotetext{
Abbreviations: CAT, catalase; FO, obese rats supplemented with fish oil; GPx, glutathione peroxidase; Keap1, Kelch-like ECH-associated protein 1; Nrf2, nuclear factor-erythroid 2 p 45-related factor 2; resv, obese rats supplemented with resveratrol; resv + FO, obese rats supplemented with resveratrol plus fish oil; ROS, reactive oxygen species; SOD, superoxide dismutase; TBARS, thiobarbituric acid-reactive species.
} 
within the cytoplasm, targeting it for ubiquitination and proteasomal degradation to maintain low levels of Nrf2. When cells are exposed to oxidative stress, a signal involving phosphorylation and/or redox modification of critical cysteine residues in Keap1 inhibits the enzymatic activity of the Keap1-E3 ubiquitin ligase complex. As a consequence, free Nrf2 translocates into the nucleus and transactivates the antioxidant response elements (for a review, see Giudice et $\left.a l .{ }^{(7)}\right)$. The Nrf2/Keap1/antioxidant response element transcriptional system regulates the expression of a battery of gene products linked to antioxidant function and detoxification phase II antioxidant enzymes, including $\mathrm{NAD}(\mathrm{P}) \mathrm{H}$ quinone reductase, glutathione transferases, thioredoxin and others (for a review, see Thornalley \& Rabbani ${ }^{(8)}$ ).

Evidence shows that the nutritional sources of antioxidants, such as polyphenolic compounds, could play a major role in enhancing the antioxidant system ${ }^{(9)}$. In this sense, resveratrol is a natural polyphenolic compound present in grapes, peanuts and red wine and has been shown to protect various tissues against oxidative damage ${ }^{(10)}$. Its high antioxidant capacity mitigates the effects of ROS in the body; due to its chemical structure $^{(11)}$, which has hydroxyl groups that act as electron donors, it neutralises the hydroxyl radical and superoxide anion, thereby preventing lipid peroxidation, protein oxidation and DNA damage ${ }^{(12)}$. In addition, the literature shows evidence that resveratrol increases the activity of enzymes such as SOD, CAT and GPx ${ }^{(13,14)}$

Long-chain PUFA represent another class of nutrient antioxidants. These contribute to maintain the structural and functional integrity of cells and cellular components ${ }^{(15)}$. In addition, studies have suggested that fish oil influences several humoral and cellular factors involved in atherogenesis and may prevent atherosclerosis, arrhythmia, thrombosis, cardiac hypertrophy and sudden cardiac death ${ }^{(16)}$. Long-chain PUFA are supplied by dietary fats, either from vegetable fats in the form of the precursor linoleic acid $(18: 2 n-6)$ of the $n-6$ series and $\alpha$-linolenic acid $(18: 3 n-3)$ of the $n-3$ series, or from fatty fishes, particularly EPA $(20: 5 n-3)$ and DHA (22:6n-3). PUFA play an important antioxidant function due to some mechanisms. Garrel et al. ${ }^{(17)}$ demonstrated that dietary supplementation with $n-3$ PUFA enhances the activity of mitochondrial SOD2 in the growing cerebrum, liver and uterus of rats. PUFA, particularly DHA, are possible to be rapidly incorporated into the phospholipids of the plasma membrane ${ }^{(18)}$ and mitochondria ${ }^{(19)}$. Therefore, PUFA could repair components of the membranes that had been attacked by superoxide anions, $\mathrm{H}_{2} \mathrm{O}_{2}$ and hydroxyl radicals ${ }^{(16)}$. In their study, El-Mowafy et al. $^{(20)}$ found that EPA markedly replenished hepatic reduced glutathione levels to near baseline, while it also blunted lipid peroxide levels, implying the alleviation of valproate-induced liver oxidative stress. PUFA can also increase the levels of CAT within the peroxisome and the cytoplasm, resulting in enhanced defences against free oxygen radicals ${ }^{(21)}$.

As noted above, obese individuals have a higher risk of mortality due to cardiovascular events. However, it remains to be investigated whether obese people are more susceptible to mortality (once cardiovascular events occurred) when compared with people with normal weight. Also, obese people have higher levels of oxidative stress, which is related to CVD. However, nutrients with antioxidant actions have demonstrated beneficial effects on health. The use of resveratrol and fish oil has shown a lower incidence of CVD. In this sense, the present study evaluated whether supplementation with resveratrol and fish oil can reduce catecholamine stressinduced mortality in obese rats and whether reduced mortality is associated with reduced evidence of oxidative stress.

\section{Experimental methods}

\section{Animals and diet}

Male Wistar rats ( 4 weeks old) were obtained from the breeding colony in the Universidade do Extremo Sul Catarinense and housed in individual cages under a $12 \mathrm{~h}$ artificial light $-12 \mathrm{~h}$ artificial dark cycle. The investigation followed the University guidelines for the use of animals in experimental studies (protocol no. 20/2011). After the acclimatisation period ( $3 \mathrm{~d})$, animals were randomly divided into lean control rats ((1) lean group, $n$ 18), which fed on a standard rodent chow, and obese rats, which fed on a high-fat diet for 2 months (Table 1). After 8 weeks, obese rats were grouped into: (2) non-supplemented obese rats (obese, $n$ 18); (3)

Table 1. Composition of the standard chow and the high-fat diet

\begin{tabular}{|c|c|c|c|c|c|c|}
\hline \multirow[b]{2}{*}{ Ingredients } & \multicolumn{3}{|c|}{ Standard chow } & \multicolumn{3}{|c|}{ High-fat diet } \\
\hline & $\mathrm{g} / \mathrm{kg}$ & $\mathrm{kcal} / \mathrm{kg}$ & $\mathrm{kJ} / \mathrm{kg}$ & $\mathrm{g} / \mathrm{kg}$ & $\mathrm{kcal} / \mathrm{kg}$ & $\mathrm{kJ} / \mathrm{kg}$ \\
\hline Maize starch & 398 & 1590 & 6653 & 116 & 462 & 1933 \\
\hline Casein & 200 & 800 & 3347 & 200 & 800 & 3347 \\
\hline Sucrose & 100 & 400 & 1674 & 100 & 400 & 1674 \\
\hline Dextrinated starch & 132 & 528 & 2209 & 132 & 528 & 2209 \\
\hline Lard & - & - & - & 312 & 2808 & 11749 \\
\hline Soyabean oil & 70 & 630 & 2636 & 40 & 360 & 1506 \\
\hline Cellulose & 50 & - & - & 50 & - & - \\
\hline Mineral mix & 35 & - & & 35 & - & - \\
\hline Vitamin mix & 10 & - & - & 10 & - & - \\
\hline L-Cystine & 3 & - & - & 3 & - & - \\
\hline Choline & 2.5 & - & - & 2.5 & - & - \\
\hline Total & 1000 & 3948 & 16518 & 1000 & 5358 & 22418 \\
\hline
\end{tabular}


obese rats supplemented with resveratrol (resv, $n$ 18); (4) obese rats supplemented with fish oil (FO, $n$ 18); (5) obese rats supplemented with resveratrol plus fish oil (resv + FO, $n$ 18). All treatments lasted 8 weeks (Fig. 1(a)).

\section{Resveratrol and fish oil supplementation}

Resveratrol (100\% purity) was purchased from Pharma Nostra LTDA and diluted in an ethanol solution of $30 \%$. A dosage of $20 \mathrm{mg}$ resveratrol $/ \mathrm{kg}$ per $\mathrm{d}$ was supplemented orally for 2 months. Fish oil was purchased from Biotik of Brazil LTDA and used without dilution. The dosage of fish oil was $0.4 \mathrm{~g} / \mathrm{kg}$ per d for 2 months. Each capsule of $1000 \mathrm{mg}$ fish oil consisted of $540 \mathrm{mg}$ EPA, $100 \mathrm{mg}$ DHA and $2 \mathrm{mg}$ vitamin E. During the period of supplementation, rats fed on a diet rich in saturated fat.

\section{Catecholaminergic stress-induced mortality protocol}

At $24 \mathrm{~h}$ after the last oral administration, catecholaminergic stress was evaluated in eighteen rats from each group. Catecholaminergic stress ( $n 10$ rats) was induced by one subcutaneous injection of $60 \mathrm{mg} / \mathrm{kg}$ of isoproterenol hydrochloride (Sigma-Aldrich). The 'no catecholaminergic stress' group ( $n 8$ rats) received a subcutaneous injection of physiological saline $(0.5 \mathrm{ml})$. At $24 \mathrm{~h}$ after the injection with subcutaneous isoproterenol, survival rates were evaluated (Fig. 1(d)). At the same time, rats unchallenged with isoproterenol were decapitated, and their myocardial and aortic tissues were homogenised in specific buffer and stored for subsequent analysis.

\section{Superoxide anion assay}

Myocardial and aortic tissues were homogenised (Polytron MR 2100; Kinematica) in $1 \mathrm{ml}$ of specific buffer ( $0.23 \mathrm{M}$-mannitol, 0.07 M-sucrose, 0.001 M-EDTA and 0.01 M-Tris-HCL; pH 7.4). The homogenate was centrifuged for $10 \mathrm{~min}$ at $600 \mathrm{~g}$ and $750 \mu \mathrm{l}$ of the supernatants were used (supernatant 1). Then, the pellet was resuspended in $1 \mathrm{ml}$ of the same buffer and homogenised again, and $750 \mu \mathrm{l}$ of the supernatants were used (supernatant 2). Aliquots of supernatant $1(750 \mu \mathrm{l})$ and supernatant $2(750 \mu \mathrm{l})$ were mixed and centrifuged for $10 \mathrm{~min}$ at $8000 \mathrm{~g}$. The pellet was resuspended with $500 \mu \mathrm{l}$ of the same buffer and centrifuged at $8000 \mathrm{~g}$ for $10 \mathrm{~min}$. Thereafter, the pellet was resuspended in $500 \mu$ l of the same buffer and stored on iced at $-70^{\circ} \mathrm{C}$. The obtained submitochondrial particles were washed twice with $140 \mathrm{~mm}-\mathrm{KCl}$ and $20 \mathrm{~mm}-$ Tris- $\mathrm{HCl}, \mathrm{pH} 7 \cdot 4$, and suspended in the same medium. Aliquots from this preparation were used to measure superoxide formation. Superoxide production was determined spectrophotometrically according to Poderoso et al. ${ }^{(22)}$. The assay is based on the superoxide-dependent oxidation of adrenaline to adenochrome at $37^{\circ} \mathrm{C}\left(E_{480 \mathrm{~nm}}=4.0 \mathrm{~mm} / \mathrm{cm}\right)$. The reaction medium consisted of $230 \mathrm{~mm}$-mannitol, $70 \mathrm{~mm}$-sucrose, $20 \mathrm{~mm}$-Tris- $\mathrm{HCl}, \mathrm{pH} 7 \cdot 4,0 \cdot 1 \mathrm{~mm}$-CAT, $1 \mathrm{~mm}$-adrenaline and $7 \mathrm{~mm}$-succinate. SOD was used at $0 \cdot 1-0.3 \mathrm{~mm}$ final concentrati ons as a negative control to confirm assay specificity. Superoxi de content was expressed as $\mathrm{nmol} / \mathrm{min}$ per $\mathrm{mg}$ protein.

\section{Thiobarbituric acid-reactive species}

The formation of TBARS during an acid-heating reaction ${ }^{(23)}$ was used as an index of lipid peroxidation. Briefly, myocardial and aortic tissues were homogenised (Polytron MR 2100;

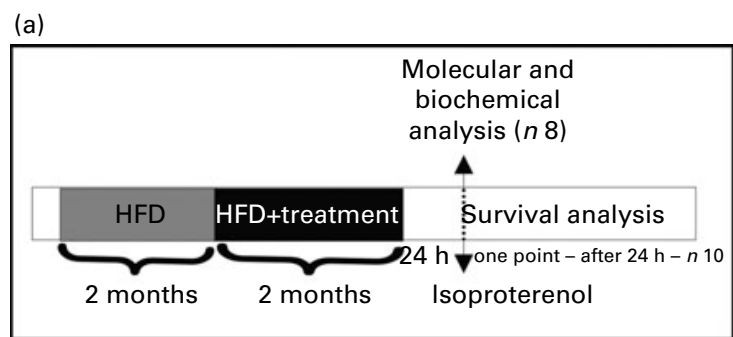

(b)

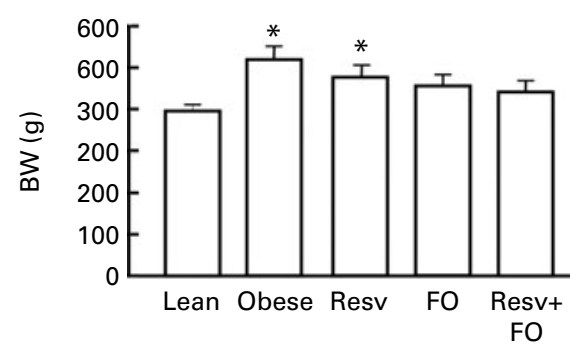

(c)

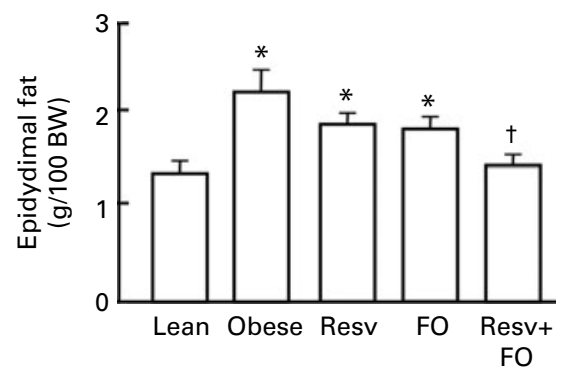

(d)

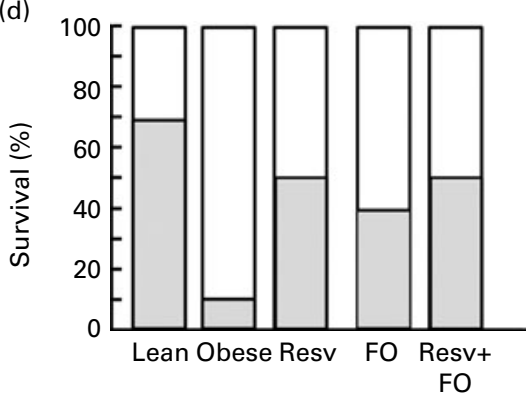

Fig. 1. Effects of resveratrol (resv) and fish oil (FO) alone or combined on the survival rate of obese rats subjected to catecholamine-induced cardiovascular stress model. (a) Schematic representation of the experimental procedures. (b) Total body weight (BW). (c) Epididymal fat. (d) Survival analysis. Values are means of eight rats per group, with their standard errors represented by vertical bars. ${ }^{*}$ Mean value was significantly different from that of the lean group $(P<0.05)$. $\dagger$ Mean value was significantly different from that of the obese group $(P<0.05)$. HFD, high-fat diet. $\sqsubset$, Isoproterenol-injected animals; $\sqsubset$, animals alive after $24 \mathrm{~h}$. 
Kinematica) with $1.0 \mathrm{ml}$ of thiobarbituric acid (TBA) buffer (10\% TCA and $1 \mathrm{ml}$ of $0.67 \%$ thiobarbituric acid). Then, $800 \mu \mathrm{l}$ of $10 \%$ ice-cold TCA were added to $400 \mu \mathrm{l}$ of myocardial and/or aortic supernatants and centrifuged at $300 \boldsymbol{g}$ for $10 \mathrm{~min}$. Thereafter, $500 \mu \mathrm{l}$ of the supernatant were transferred to a pyrex tube and incubated with $500 \mu \mathrm{l}$ of $0.67 \%$ TBA in $7 \cdot 1 \%$ sodium sulphate on a boiling water-bath for $30 \mathrm{~min}$. The tubes containing the mixture were allowed to cool on running tap water for $5 \mathrm{~min}$. The resulting pink-stained TBARS was determined in a spectrophotometer at $532 \mathrm{~nm}$. A calibration curve was performed using 1,1,3,3-tetramethoxypropane, and each curve point was subjected to the same treatment as supernatants. TBARS values were calculated as nmol TBARS/mg protein. The results of the TBARS method carry some limitations. First, the majority of the free radicals measured are formed during the heating procedure, thus leading to artificially larger values than encountered in the samples. Second, TBA reacts with different oxidised species, not only malonaldehyde; thus, it lacks specificity to lipid free radicals. Despite this, it could be used as a general marker of oxidative damage, rather than as a specific marker of lipid peroxidation, but it is widely used and accepted in the literature.

\section{Protein carbonyls}

Oxidative damage to protein was determined by measuring carbonyl groups based on the method described by Levine et $a l .{ }^{(24)}$ with modifications. Briefly, myocardial and aortic tissues were homogenised (Polytron MR 2100; Kinematica) with $1.0 \mathrm{ml}$ of carbonyl buffer (120 mM-KCL and $30 \mathrm{~mm}-\mathrm{KH}_{2} \mathrm{PO}_{4}$ ) and centrifuged for $15 \mathrm{~min}$ at $12000 \mathrm{~g}$. Then, the amount of protein was determined in the samples. This quantity was aliquoted into two Eppendorf tubes. To each tube, $100 \mu \mathrm{l}$ of $20 \%$ TCA (TCA dissolved in water) were added, and allowed to mix for $5 \mathrm{~min}$ on ice. They were then centrifuged for $5 \mathrm{~min}$ at $14000 \mathrm{~g}$. The supernatant was discarded and the pellet redissolved in $100 \mu \mathrm{l} \mathrm{NaOH}$ at $0 \cdot 2 \mathrm{M}$. Then, $400 \mu \mathrm{l}$ of $10 \mathrm{~mm}-2,4-$ dinitrophenylhydrazine in $2.5 \mathrm{M}-\mathrm{HCl}$ or $400 \mathrm{ml} 2.5 \mathrm{M}-\mathrm{HCl}$ were added to $100 \mu \mathrm{l}$ samples of supernatants and incubated for $2 \mathrm{~h}$.

Samples were vortexed every 15 min, extracted with $100 \mu \mathrm{l}$ of $20 \% \mathrm{TCA}$, and then spun for $5 \mathrm{~min}$ at $14000 \mathrm{~g}$. The precipitates were washed once with $1 \mathrm{ml}$ of $10 \%$ TCA, followed by three washes with $1 \mathrm{ml}$ ethanol-ethyl acetate (1:1) to remove free 2,4-dinitrophenylhydrazine and lipid contaminants. Precipitates from 2,4-dinitrophenylhydrazine-treated samples were dissolved in $2 \mathrm{ml}$ of $6 \mathrm{~m}$-guanidine hydrochloride solution at $37^{\circ} \mathrm{C}$ for $10 \mathrm{~min}$. Carbonyl contents were calculated from peak absorbance (355-390 nm) using an absorption coefficient of $22000 \mathrm{~mol} / 1 \times \mathrm{cm}$ against pellets derived from the $2.5 \mathrm{M}-\mathrm{HCl}$-treated samples, which were also used to calculate the protein contents against a bovine serum albumin standard dissolved in $6 \mathrm{~m}$-guanidine hydrochloride and read at $370 \mathrm{~nm}$.

\section{Catalase activity}

In order to determine CAT activity, tissue samples were hom-

ogenised in $10 \mathrm{ml}$ of $50 \mathrm{~mm}$-phosphate buffer ( $137 \mathrm{~mm}-\mathrm{NaCl}$,
$0.27 \mathrm{~mm}-\mathrm{Na}_{2} \mathrm{PO}_{4}$ and $\left.1.1 \mathrm{~mm}-\mathrm{KH}_{2} \mathrm{PO}_{4}\right)$ and the resulting suspension was centrifuged at $3000 \mathrm{~g}$ for $10 \mathrm{~min}$. Next, $40 \mu \mathrm{l}$ $\mathrm{H}_{2} \mathrm{O}_{2}$ were added to $25 \mathrm{ml}$ of phosphate buffer, and thus $10 \mu \mathrm{l}$ of sample supernatants were added to $1 \mathrm{ml}$ of phosphate buffer containing $\mathrm{H}_{2} \mathrm{O}_{2}$. CAT activity was measured based on the rate of the decrease in $\mathrm{H}_{2} \mathrm{O}_{2}(10 \mathrm{~mm})$ absorbance at $240 \mathrm{~nm}^{(25)}$

\section{Superoxide dismutase activity}

Myocardial and aortic samples were homogenised in $1 \mathrm{ml}$ glycine buffer ( $50 \mathrm{~mm}, \mathrm{pH} 10 \cdot 2)$ and the resulting suspension was centrifuged at $3000 \mathrm{~g}$ for $10 \mathrm{~min}$. SOD activity was determined according to Bannister \& Calabrese ${ }^{(26)}$ using a spectrophotometric assay based on the superoxide-dependent oxidation of adrenaline to adrenochrome at $32{ }^{\circ} \mathrm{C}$. Absorption was measured at $480 \mathrm{~nm}\left(E_{480 \mathrm{~nm}}=4.0\right.$ per $\left.\mathrm{mm} \times \mathrm{cm}\right)$. The reaction medium consisted of $50 \mathrm{~mm}$-glycine buffer, $\mathrm{pH} 10 \cdot 2$, $0 \cdot 1 \mathrm{~mm}-\mathrm{CAT}$ and $1 \mathrm{~mm}$-adrenaline. SOD specific activity was represented as $\mathrm{IU} / \mathrm{mg}$ protein.

\section{Glutathione peroxidase activity}

GPx activity was modified from the method of Flohé \& Günzler $^{(27)}$. For the enzyme reaction, $0 \cdot 2 \mathrm{ml}$ of the supernatant were placed into a tube and mixed with $0.4 \mathrm{ml}$ reduced glutathione (Sigma product, analytical grade), and the mixture was put into an ice bath for $30 \mathrm{~min}$. Then, the mixture was centrifuged for $10 \mathrm{~min}$ at $3000 \mathrm{~g}, 0.48 \mathrm{ml}$ of the supernatant were placed into a cuvette, and $2.2 \mathrm{ml}$ of $0.32 \mathrm{M}-\mathrm{Na}_{2} \mathrm{HPO}_{4}$ and $0.32 \mathrm{ml}$ of $1.0 \mathrm{~mm}-5,5^{\prime}$-dithio-bis (2-nitrobenzoic acid) (Sigma) were added for colour development. Absorbance at a wavelength of $412 \mathrm{~nm}$ was measured in a spectrophotometer after $5 \mathrm{~min}$. Enzyme activity was calculated as a decrease in reduced glutathione within the reaction time when compared with that in the non-enzyme reaction, and results expressed as IU/mg protein.

\section{Protein analysis by immunoblotting}

Myocardial and aortic tissues were homogenised in extraction buffer ( $1 \%$ Triton-X 100, $100 \mathrm{mm-Tris,} \mathrm{pH} \mathrm{7.4,} \mathrm{containing}$ $100 \mathrm{~mm}$-sodium pyrophosphate, $100 \mathrm{~mm}$-sodium fluoride, $10 \mathrm{~mm}$-EDTA, $10 \mathrm{~mm}$-sodium vanadate, $2 \mathrm{~mm}$-phenylmethanesulphonylfluoride (PMSF) and $0.1 \mathrm{mg}$ aprotinin $/ \mathrm{ml}$ ) at $4{ }^{\circ} \mathrm{C}$ with a Polytron MR 2100 (Kinematica). The extracts were centrifuged at $9000 \mathrm{~g}$ at $4{ }^{\circ} \mathrm{C}(5804 \mathrm{R}$; Eppendorf $\mathrm{AG})$ for $40 \mathrm{~min}$ to remove insoluble material. The supernatants were used for protein quantification according to the Bradford method. Proteins were denatured by boiling in a sample buffer containing $100 \mathrm{~mm}$ - dithiothreitol (DTT), run on SDS-PAGE and transferred to nitrocellulose membranes. The membranes were blocked, probed and blotted with primary antibodies. The antibodies used for immunoblotting were anti-SOD2, anti-CAT, antiGPx1/2, TNF- $\alpha$, IL-1 $\beta$, NF-кB/p 65 and $\beta$-actin (Santa Cruz Biotechnology). Chemiluminescent detection was performed with horseradish peroxidase-conjugated secondary antibodies (Thermo Scientific). Autoradiographs of the membranes were 
taken for the visualisation of protein bands. The results of the blots are presented as direct comparisons of the area of the apparent bands in autoradiographs and quantified by densitometry using Scion Image software (ScionCorp).

\section{Statistical analysis}

Biochemical data are expressed as means with their standard errors and analysed statistically by one-way ANOVA followed by the Bonferroni post hoc test ( $n 8$ animals per group). Statistical analysis of the Western blot was performed as the mean area of the apparent band (SEM), but results are expressed as representative bands (graphics not shown, $n 8$ animals per group). Survival analysis was performed $24 \mathrm{~h}$ after experimental infarction ( $n 10$ animals per group). Animal survival was compared using the $\chi^{2}$ test, because we had a single time-point observation. The level of significance was set at $P<0 \cdot 05$. For analysis of the data, the Statistical Package for the Social Sciences version 16.0 for Windows (SPSS, Inc.) was used.

\section{Results}

\section{Resveratrol and fish oil supplementation reduces mortality} induced by catecholamine stress

We evaluated whether the supplementation of resveratrol and fish oil reduced body weight and epididymal fat. Diet-induced obesity led to increased body weight in the obese group when compared with the lean group. However, supplementation did not reduce body weight (Fig. 1(b)). In addition, diet-induced obesity caused increased epididymal fat when compared with the lean group (Fig. 1(c)). Supplementation of resveratrol or fish oil alone did not reduce epididymal fat, but when administered in combination, epididymal fat diminished significantly (Fig. 1(c)).

Administration of isoproterenol produces high rates of death $^{(28)}$. In the present study, obese rats (obese group) presented the highest percentage $(90 \%)$ of death when compared with lean rats (lean group) (30\%) (Fig. 1(d)). However, resveratrol (50\%) and fish oil (40\%) increased the rate of survival of the animals that received isoproterenol, demonstrating the beneficial effect of supplementation in this model (Fig. 1(d)). No higher rate of survival was observed (50\%) in the group supplemented with resveratrol and fish oil (resv + FO) in comparison with resveratrol or fish oil alone. Survival analysis was performed $24 \mathrm{~h}$ after inducing catecholaminergic stress (n 10 animals per group). Animal survival was compared using the $\chi^{2}$ test $(P=0.019)$ because we had a single time-point observation.

\section{Levels of superoxide and oxidative damage in the myocardium and aorta of obese rats after resveratrol and fish oil supplementation}

In the obese group, a significant increase in superoxide production in the myocardium (Fig. 2(a)) and aorta (Fig. 3(a)) was noted. However, resveratrol and fish oil supplementation diminished this level in the myocardium (Fig. 2(a)) and aorta
(Fig. 3(a)). We also noted superoxide reduction in both the myocardium and aorta of the resv + FO group, which did not differ significantly from the results of isolated supplementation (Figs. 2(a) and 3(a)). Oxidative damage to lipids was assessed based on TBARS levels in the myocardium and aorta. However, the results of the TBARS approach may have some limitations. First, a majority of the free radicals measured are formed during the heating procedure, thus leading to artificially larger values. Second, TBA reacts with different oxidised species, not only malonaldehyde; thus it lacks specificity to lipid free radicals. Despite this, it could be used as a general marker of oxidative damage, rather than as a specific marker of lipid peroxidation. However, this technique has been widely used and accepted. In the myocardium of obese rats, TBARS levels increased when compared with the lean group (Fig. 2(b)). Supplementation (resv or FO group or resv plus FO group) reduced TBARS levels when compared with the obese group. In the aortic tissue, TBARS levels increased in the obese group when compared with the lean group (Fig. 3(b)). However, after supplementation, these values diminished (Fig. 3(b)). The resveratrol plus fish oil supplementation did not enhance the myocardial (Fig. 2(b)) and aortic (Fig. 3(b)) TBARS levels. We evaluated the carbonyl groups to assess oxidative damage to proteins in the myocardial and aortic tissues (Figs. 2(c) and 3(c), respectively). The present findings demonstrated an increase in carbonyl content in the myocardium of the obese group when compared with the lean group (Fig. 2(c)); it was reverted after the supplementation treatment. In the aorta of obese rats, the carbonyl content increased (Fig. 3(c)). Whereas, it reduced in the resv, FO and resv + FO groups when compared with the obese group (Fig. 3(c)). Combined supplementation showed no difference in values in the myocardium when compared with the isolated supplementation (Fig. 2(c)). However, combined supplementation generated greater differences in values in the aorta when compared with the isolated supplementation (Fig. 3(c)).

\section{Activities of antioxidant enzymes in the myocardium and aorta of obese rats after resveratrol and fish oil supplementation}

SOD activity diminished in the myocardium of the obese group when compared with the lean group (Fig. 2(d)). However, it was reverted after supplementation (Fig. 2(d)). SOD activity also diminished in the aortic tissue of obese rats. However, it was reverted after supplementation (Fig. 3(d)). CAT (an antioxidant enzyme responsible for converting $\mathrm{H}_{2} \mathrm{O}_{2}$ to water) activity remained unchanged in the myocardium and aorta of both obese and supplemented groups (Figs. 2(e) and $3(\mathrm{e})$, respectively). Another enzyme that converts $\mathrm{H}_{2} \mathrm{O}_{2}$ into water is GPx. Obese rats showed reduced GPx activity in the myocardium and aorta (Figs. 2(f) and 3(f), respectively). Supplementation with resveratrol increased GPx activity in the myocardium (Fig. 2(f)) and aorta (Fig. 3(f)) when compared with the obese group. An increase in GPx activity was also observed in the FO group in the myocardium and aorta when compared with the obese group (Figs. 2(f) and 3(f), 
(a)

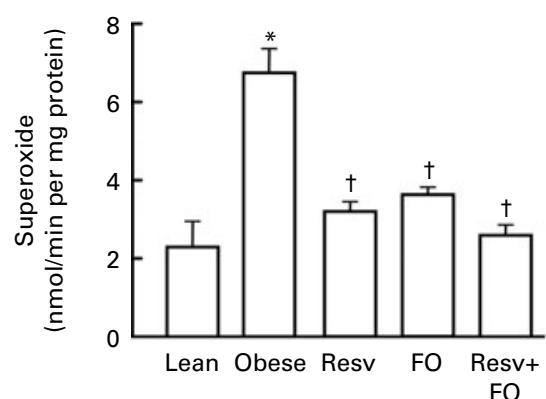

(d)

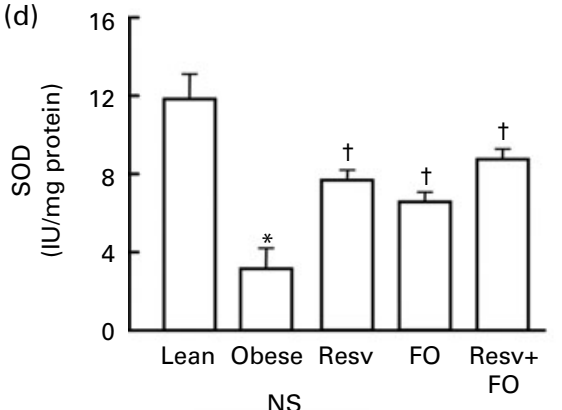

(b)

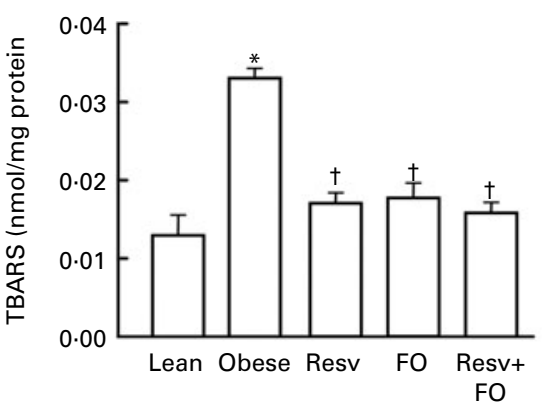

(e) 8 (c)

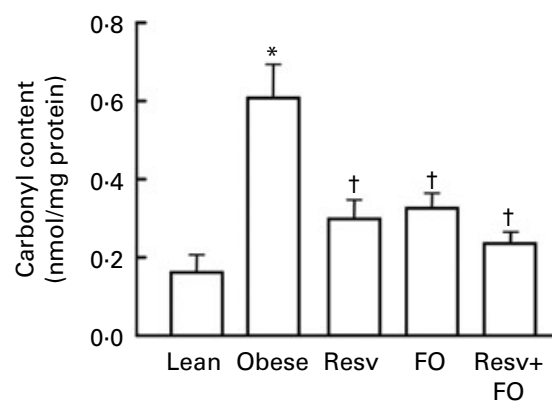

(f)

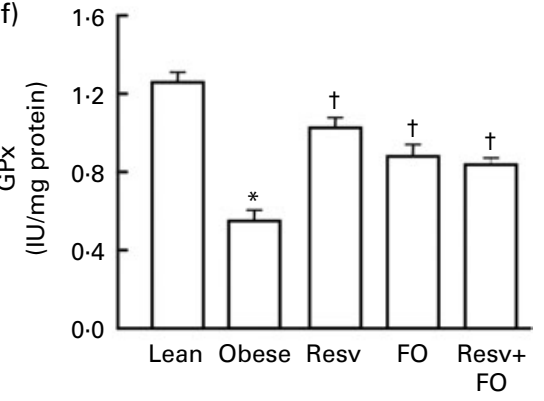

(g)

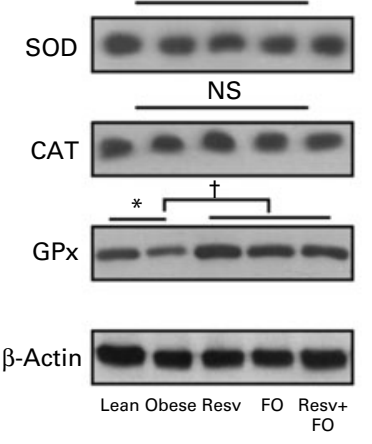

(j)

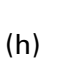

(h)
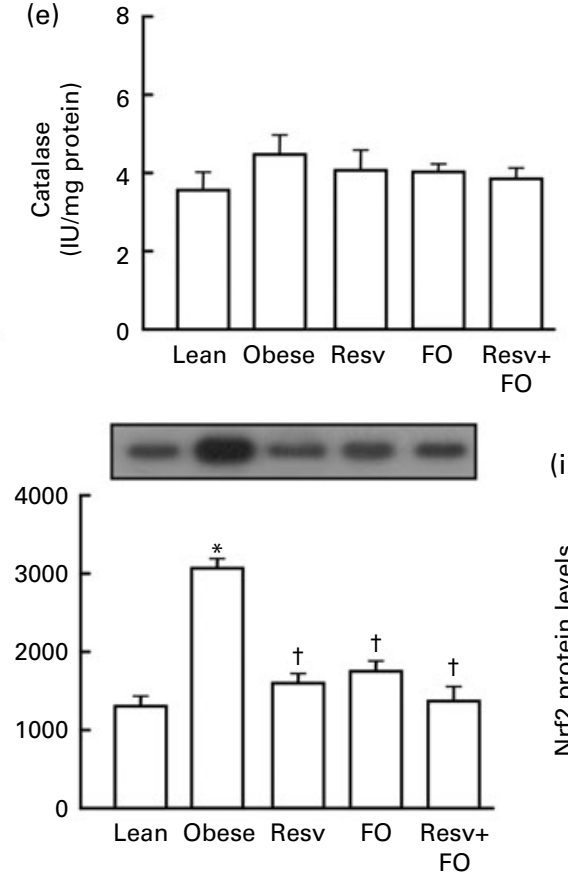
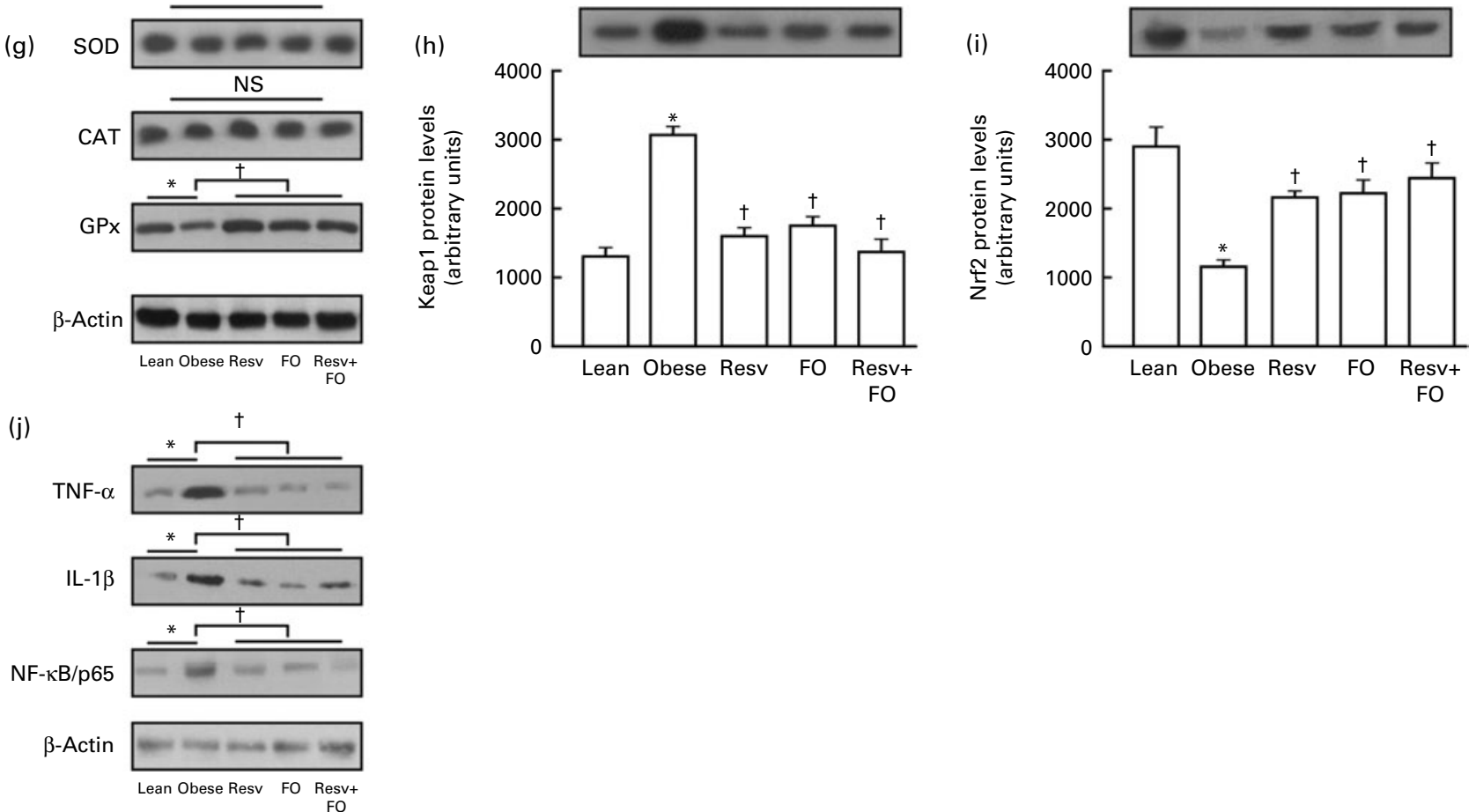

Fig. 2. Superoxide, oxidative damage, activity and protein levels of antioxidant enzymes in the myocardium of obese rats after resveratrol (resv) and fish oil (FO) supplementation. (a) Superoxide production, (b) thiobarbituric acid-reactive substances (TBARS) and (c) carbonyl content. (d) Superoxide dismutase (SOD), (e) catalase (CAT) and (f) glutathione peroxidase (GPx) activities. Antioxidant enzymes activities are expressed as IU/mg protein. In (g), SOD, CAT, GPx and $\beta$-actin protein levels are shown; antioxidant enzyme protein levels are expressed as representative bands (graphics not shown). (h) Kelch-like ECH-associated protein 1 (Keap1) and (i) nuclear factor-erythroid 2 p45-related factor 2 (Nrf2) protein levels are shown. In (j), TNF- $\alpha, \mathrm{IL}-1 \beta, \mathrm{NF}-\mathrm{kB} / \mathrm{p} 65$ and $\beta$-actin are shown. Myocardial tissues from obese rats were prepared as described in the Methods section. Values are means of eight rats per group, with their standard errors represented by vertical bars. * Mean value was significantly different from that of the lean group $(P<0.05)$. $†$ Mean value was significantly different from that of the obese group $(P<0.05)$. 
(a)

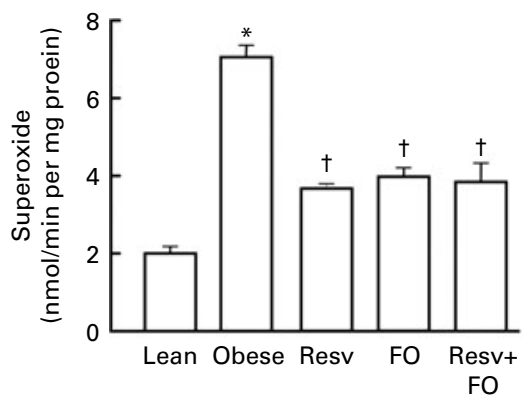

(d)

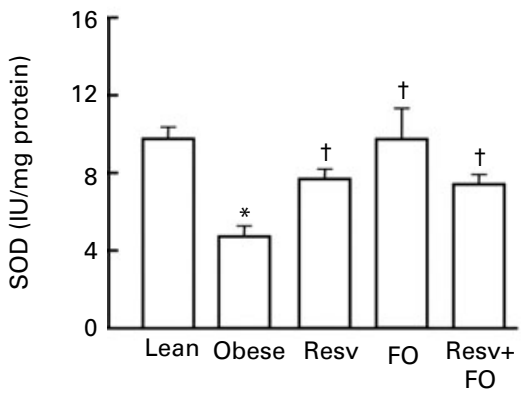

(b)

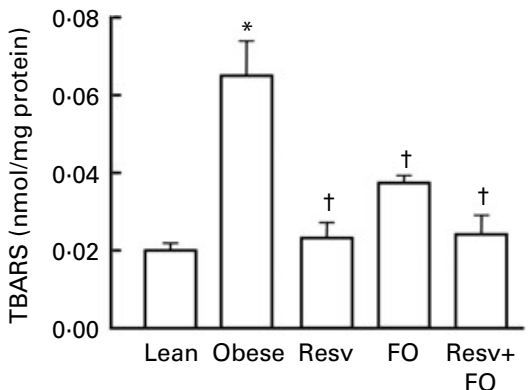

(e)

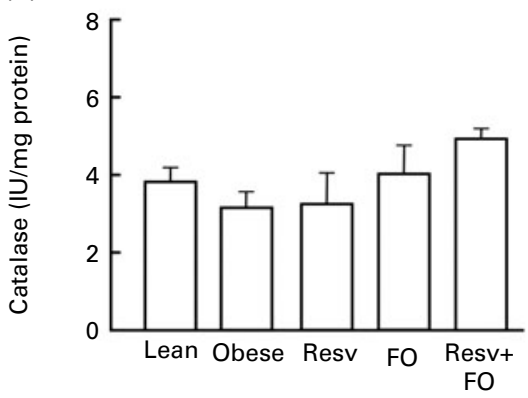

(c)

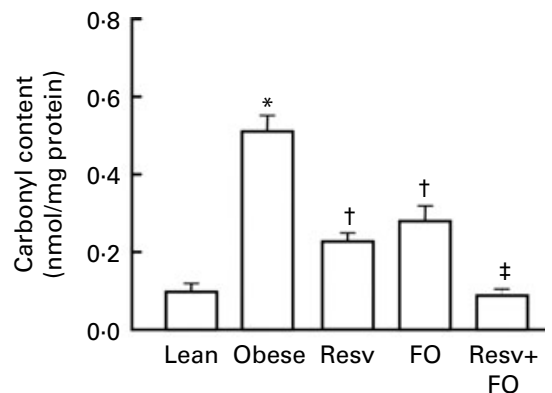

(f)

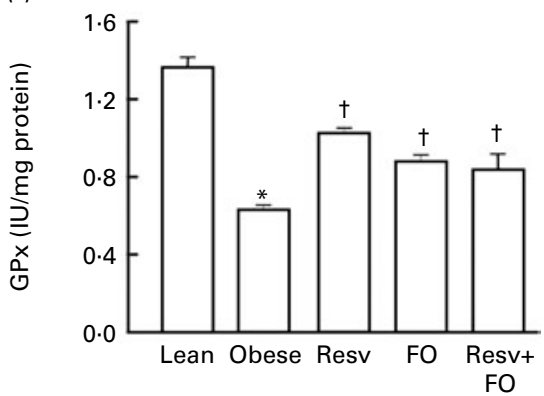

(g)
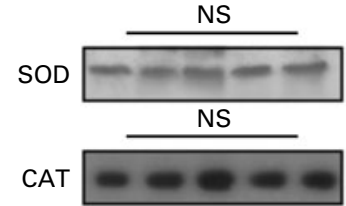

NS
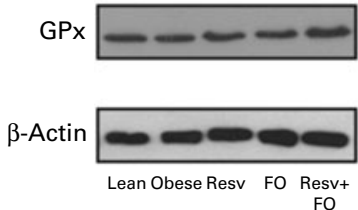

(j)

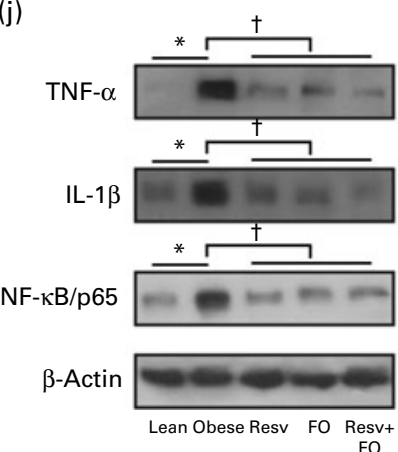

(h)

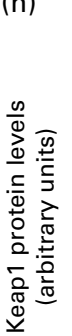

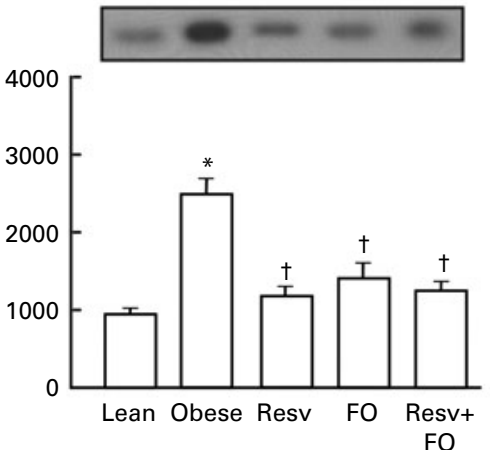

(i)

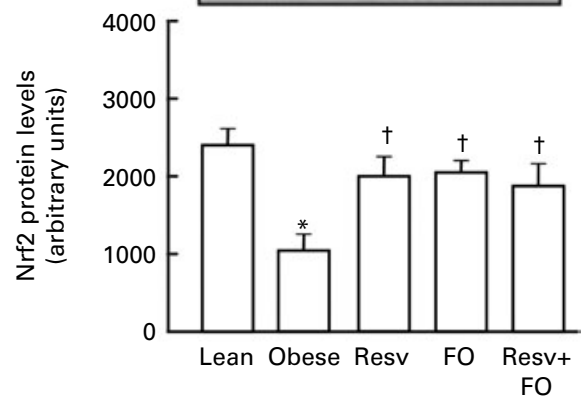

Fig. 3. Superoxide, oxidative damage, activity and protein levels of antioxidant enzymes in the aorta of obese rats after resveratrol (resv) and fish oil (FO) supplementation. (a) Superoxide production, (b) thiobarbituric acid-reactive substances (TBARS) and (c) carbonyl content. (d) Superoxide dismutase (SOD), (e) catalase (CAT) and (f) glutathione peroxidase (GPx) activities. Antioxidant enzyme activities are expressed as IU/mg protein. In (g), SOD, CAT and GPx protein levels are shown; antioxidant enzyme protein levels are expressed as representative bands (graphics not shown). (h) Kelch-like ECH-associated protein 1 (Keap1) and (i) nuclear factor-erythroid 2 p45-related factor 2 (Nrf2) protein levels are shown and expressed as arbitrary units. In (j), TNF- $\alpha$, IL-1 $\beta$, NF-kB/p65 and $\beta$-actin are shown. Aortic tissues from obese rats were prepared as described in the Methods section. Values are means of eight rats per group, with their standard errors represented by vertical bars. * Mean value was significantly different from that of the lean group $(P<0.05)$. $\dagger$ Mean value was significantly different from that of the obese group $(P<0.05)$. $¥$ Mean value was significantly different from those of the resv and FO supplementation-alone groups $(P<0.05)$. 
respectively). GPx activity in the myocardium and aorta of the resv + FO group also increased; however, it did not differ much from the group offered the isolated supplements.

\section{Protein levels of the antioxidant enzyme and the} nuclear factor-erythroid 2 p45-related factor 2/Kelch-like ECH-associated protein 1 pathway in the myocardium and aorta of obese rats after resveratrol and fish oil supplementation

SOD protein levels did not change in the myocardium and aorta of both obese and supplemented groups (Figs. 2(g) and $3(\mathrm{~g})$, respectively). Also, CAT protein levels remained unchanged in the myocardium and aorta of both obese and supplemented groups (Figs. 2(g) and 3(g), respectively). GPx protein levels in the myocardium diminished in the obese group when compared with the lean group (Fig. 2(g)). In contrast, these values increased in the supplemented groups (Fig. 2(g)). No difference among the isolated supplementation was observed. In the aorta, no significant alteration was observed among all the groups evaluated (Fig. 3(g)).

Next, we evaluated the Keap1/Nrf2 pathway affected by redox status. In the myocardium of obese rats, Keap1 increased, whereas it reduced in both supplemented groups (Fig. 2(h)). In the aorta of obese rats, Keap1 protein levels also increased. However, the supplementation treatment markedly reduced it (Fig. 3(h)). No difference was observed in Keap1 protein levels in the myocardium and aorta between the supplementation treatments (Figs. 2 and 3(h)). In the myocardium of obese rats, Nrf2 reduced, whereas it increased in both supplemented groups (Fig. 2(i)). In the aorta of obese rats, Nrf2 protein levels also reduced. However, the supplementation treatment markedly increased it (Fig. 3(i)). No difference was observed in Nrf2 protein levels in the myocardium and aorta between the supplementation treatments.

\section{Pro-inflammatory status in the myocardium and aorta of} obese rats after resveratrol and fish oil supplementation

In addition, pro-inflammatory status was evaluated; utilised for this the protein levels of TNF- $\alpha$, IL- $1 \beta$ and NF- $\kappa$ B. TNF- $\alpha$ and IL- $1 \beta$ protein levels increased in the obese group when compared with the lean group in the myocardium (Fig. 2(j)) and aorta (Fig. 3(j)), whereas it reduced in all the supplemented groups. A similar result was observed in NF- $\mathrm{B}$ protein levels (Figs. 2 and 3(j)). However, this pro-inflammatory molecule was also reverted in the supplemented groups. No difference was observed in TNF- $\alpha$, IL- $1 \beta$ and NF- $\kappa$ B protein levels in the myocardium and aorta between the supplementation treatments.

\section{Discussion}

Obesity is a major risk factor for several illnesses, including hypertension, diabetes and myocardial infarction ${ }^{(29,30)}$. Nevertheless, the association of obesity as an independent factor with cardiovascular dysfunction, both at arterial and cardiac myocyte levels, is becoming more apparent ${ }^{(29,30)}$. Patients with morbid obesity have higher rates of sudden unexpected cardiac-related death $^{(31,32)}$. It has been argued that oxidative stress may be involved in this process ${ }^{(33-35)}$. Thus, we hypothesise that resveratrol and fish oil supplementation could have important cardioprotective effects, ultimately reducing the rates of catecholaminergic stress-induced mortality. The present results show that catecholaminergic stress produces higher rates of death in obese, while resveratrol and fish oil supplementation reduced it. The present data suggest that this was related to minor oxidant status in myocardial and aortic tissues. In addition, the supplementation treatments also reduced inflammatory status. These results were observed without body-weight modification, suggesting that the reduction in mortality occurs not due to improved weight management. Combined supplementation showed lower epididymal fat than did isolated supplementation, but this was not reflected in survival rates. The present results are in agreement with those of Zhang et al. ${ }^{(36)}$, who found that resveratrol was unable to change the body weight. The authors have also suggested that the therapeutic effects of resveratrol, particularly in vascular complications, occurred independently of weight loss. In addition, Gaiva et al. ${ }^{(37)}$ showed that dietary DHA and/or EPA on body weight have a merely modest effect.

To evaluate the cardioprotective effects of resveratrol and/ or fish oil for this animal model of obesity, we induced catecholamine stress by isoproterenol. A key finding of the present study was that supplementation treatments (both isolated and combined) increased the survival rate in dietinduced obesity rats. The results suggest that rats with dietinduced obesity demonstrated lower cardiovascular resistance to isoproterenol-induced mortality. On the other hand, supplementation treatments exerted significant cardioprotective effects. The diet used in the present study mimics an environmental situation, especially the occidental diet. Diet-induced obesity is widely used and accepted in the literature. However, a diet rich in saturated fat has been associated with cardiac arrhythmia; thus, we cannot declare that higher mortality in this animal model was due to obesity per se or to high saturated fat. Nevertheless, the results clearly show higher survival rates after supplementation.

As noted earlier, excessive production of ROS in both the aorta and myocardium may be involved in cardiovascular events. In order to assess the possible link between mortality and oxidative damage in obese rats, we analysed the levels of superoxide and oxidative damage. Obese rats had higher levels of superoxide anion and markers of damage to lipids and proteins in the myocardium and aorta. Ozata et al. ${ }^{(38)}$ observed that obesity was associated with increased oxidative damage. They suggested that increased oxidative damage was due to increased superoxide formation. In supplemented obese rats, there was a significant reduction in the levels of both TBARS and carbonyl contents in both myocardial and aortic tissues, suggesting that supplementation was able to reduce oxidative damage in obese rats, possibly due to reduced superoxide levels. The mechanism by which resveratrol reduces the formation of superoxide may be linked to its chemical structure $^{(11)}$, which has hydroxyl groups that act as scavengers of free radicals; this may have reduced oxidative 
damage in lipids and proteins ${ }^{(12,39)}$. Decreased superoxide levels and oxidative damage occurred in parallel with increased activity of antioxidant enzymes, except for CAT activity. In animals that received supplementation, we observed an increase in the activity of SOD in both tissues. The literature shows that resveratrol increases the activity of SOD ${ }^{(40)}$. The catalysis of $\mathrm{H}_{2} \mathrm{O}_{2}$ by CAT is significant because, in the presence of $\mathrm{Fe}, \mathrm{H}_{2} \mathrm{O}_{2}$ leads to the formation of hydroxyl radicals ( $\mathrm{OH}^{*}$, Fenton reaction), which are highly reactive and could damage biomolecules. In both tissues, no differences were observed in the activity and protein levels of CAT but compensated by an increase in GPx activity. GPx is a Se-dependent enzyme that catalyses the reduction of $\mathrm{H}_{2} \mathrm{O}_{2}$ and organic hydroperoxides to water and alcohol, respectively, using glutathione as an electron donor. The present results show that both the activity and protein levels of GPx increased significantly in the supplemented groups in the myocardium. In the aorta, we observed an increase in only GPX activity in all the supplemented groups. Spanier et al. ${ }^{(41)}$ suggested that resveratrol is capable of inducing an increase in the activity and mRNA expression of endogenous antioxidant defences, such as SOD and GPX, in human endothelial cells. In addition, resveratrol has been shown to have cardioprotective effects during ischaemia/reperfusion through its ROS-scavenging activity ${ }^{(14)}$.

In the present study, obesity was induced by a saturated fat (lard) diet. Saturated fat has long been shown to increase arrhythmia and mortality risk $^{(42)}$. The final common pathway for most cardiac deaths is arrhythmia. Mortality from isoproterenol injection was most probably due to sudden arrhythmia ${ }^{(43)}$. Dietary $n-6$ and $n-3$ PUFA have been shown to protect against arrhythmia, with the greatest protection observed with fish oil (for reviews, see McLennan \& Abeywardena ${ }^{(42)}$ and Gudbjarnason $\left.{ }^{(44)}\right)$. On the other hand, fish oil has long been established as potently anti-arrhythmic. In fact, Gudbjarnason ${ }^{(44)}$ showed that cod-liver oil prevented catecholamine-induced mortality in rats, due to different fatty acid compositions of individual phospholipids in the sarcolemma, and that the balance between $n-6$ and $n-3$ fatty acids in cellular phospholipids seems to play an important role in sudden cardiac death ${ }^{(44)}$. In the present study, supplementation with fish oil proved beneficial in protecting the myocardium and aorta from oxidative damage, mainly by increasing the activity of SOD and GPX. Barbosa et $_{\text {al }}{ }^{(45)}$ suggested that fish oil can be a neutraliser of free radicals, protecting individuals against oxidative stress; however, these authors did not elaborate the mechanism by which this occurs.

A hallmark of the antioxidant defence system is the activation of the transcription factor Nrf2. The redox-sensitive transcription factor Nrf2 plays a pivotal role in cellular defence against oxidative stress via transcriptional up-regulation of phase II defence enzymes. We observed that Nrf2 protein levels reduced in the myocardium and aorta of obese rats. Supplementation with resveratrol and fish oil (isolated or combined) increased the Nrf2 protein levels. Nrf2 is constitutively controlled by the repressor protein Keap1, which acts as a molecular sensor of disturbances in cellular homeostasis. Keap1 functions as an adapter between Nrf2 and Cullin 3 ubiquitin ligase (Cul3) proteins, and this binding promotes the continued degradation of Nrf2 (for a review, see Giudice et $\left.a l .{ }^{(7)}\right)$. Interestingly, the activation of the Nrf2 antioxidant pathway has a role in cardioprotection ${ }^{(46)}$. Several studies have shown evidence that resveratrol induces $\mathrm{Nrf}_{2}^{(47-50)}$. One explanation to support this was that resveratrol facilitates the degradation of Keap1. The finding that $n-3$ PUFA activate the Nrf2/keap1 pathway deserves further investigation; however, the expression and activity of key enzymes involved in antioxidant and phase II detoxification pathways, all mediated by $\mathrm{Nrf} 2$, have been found to be elevated in the heart of mice fed with an $n-3$ PUFA diet ${ }^{(51)}$. This increase was paralleled by increased levels of 4-hydroxyhexenal protein adducts, an aldehyde formed from the peroxidation of $n-3$ PUFA $^{(51)}$. In addition, 4-hydroxyhexenal was able to stimulate the phase II detoxification pathway through the activation of Nrf2, preventing oxidative stress-induced cytotoxicity in vascular endothelial cells ${ }^{(52)}$. It provides at least a partial explanation for the cardioprotective effects of $n$ - 3 PUFA.

A variety of biological effects of EPA and DHA have been demonstrated from feeding studies with fish or fish oil supplements in human subjects and animals (for a review, see Mori \& Beilin $\left.{ }^{(53)}\right)$. Dietary $n-3$ fatty acids have a variety of anti-inflammatory and immune-modulating effects that may be of relevance to atherosclerosis and its clinical manifestations of myocardial infarction, sudden death and stroke ${ }^{(54,55)}$. In addition, the anti-inflammatory effect of resveratrol has been studied. The anti-inflammatory activity of resveratrol may be related to interference with the NF- $\kappa \mathrm{B}$ signalling pathway, which regulates the expression of various genes involved in inflammation ${ }^{(54,55)}$. With this in mind, we evaluated TNF- $\alpha$, IL-1 $\beta$ and NF- $\kappa$ B. We observed increased pro-inflammatory status in the myocardium and aorta of diet-induced obesity rats, which was diminished in the supplemented group. In fact, depending on their concentrations, reactive species can either act as molecules that promote cell survival (at low to moderate concentrations) or, at high concentrations, induce irreversible cellular damage and death. High ROS levels can induce NF- $\mathrm{B}$ activation, inflammation, apoptosis or necrosis (for a review, see Rodrigo et al. $^{(56)}$ ). $\mathrm{NF}-\kappa \mathrm{B}$ and activator protein 1 pathways are crucial in the expression of pro-inflammatory genes, such as $T N F-\alpha$ and $I L-1 \beta^{(57)}$. Taken together with NRF2, we can suggest that high ROS levels can induce NF- $\mathrm{KB}$ activation and inflammation; low to moderate levels can enhance the antioxidant response, via Nrf2 activation. Elegant work of Kaneko et $a l .{ }^{(58)}$ has shown that resveratrol prevented the development of $\mathrm{CaCl}_{2}$-induced abdominal aortic aneurysm in association with the attenuation of neoangiogenesis, oxidative stress and chronic inflammation. Using mitochondria-targeted vitamin $\mathrm{E}$ in a rat pneumonia-related sepsis model, Zang et $a l{ }^{(59)}$ examined the role of mitochondrial ROS in sepsismediated myocardial inflammation and subsequent cardiac contractile dysfunction. They have suggested that targeted scavenging of mitochondrial ROS protects mitochondrial function, attenuates tissue-level inflammation and improves whole-organ activities in the heart during sepsis. 
Taken together, the present data suggest that oxidative stress in the myocardium and aorta, directly or through inflammatory activation, may be associated with increased mortality in obese rats after catecholamine-induced cardiovascular. The present study also show that supplementation with resveratrol and fish oil reduced oxidative stress and inflammatory status and, in turn, reduced mortality. However, these data should be viewed with prudence since the answer to obesity is not the use of supplements but rather the adoption of a correct lifestyle and diet. In addition, future studies of our group intend to use another obesity model, since saturated fat feeding per se increase the risk of cardiac arrhythmias.

\section{Acknowledgements}

The present study was supported by the Conselho Nacional de Desenvolvimento Científico e Tecnológico, Fundação de Amparo a Pesquisa do Estado de Santa Catarina and Universidade do Extremo Sul Catarinense. All experiments were completed at the Universidade do Extremo Sul Catarinense. The authors' contributions are as follows: P. R. M. A. and C. T. D. S. contributed to the conception, design, analysis and interpretation of the data, drafting and critically revising of the manuscript for important intellectual content; S. O. M. and M. F. V. contributed to the conception and design of the study; T. F. L., J. E., D. R. S., S. V. P., F. S. L. and R. A. P. contributed to the conception, design, analysis and interpretation of the data. The authors report no conflicts of interest.

\section{References}

1. James PT, Rigby N \& Leach R (2004) International Obesity Task Force. The obesity epidemic, metabolic syndrome and future prevention strategies. Eur J Cardiovasc Prev Rehabil 11, 3-8

2. Adams KF, Schatzkin A, Harris TB, et al. (2006) Overweight, obesity, and mortality in a large prospective cohort of persons 50 to 71 years old. $N$ Engl J Med 355, 763-778.

3. Lakka TA, Lakka HM, Salonen R, et al. (2001) Abdominal obesity is associated with accelerated progression of carotid atherosclerosis in men. Atherosclerosis 154, 497-504.

4. Kenchaiah S, Evans JC, Levy D, et al. (2002) Obesity and the risk of heart failure. $N$ Engl J Med 347, 305-313.

5. Vincent HK \& Taylor AG (2006) Biomarkers and potential mechanisms of obesity-induced oxidant stress in humans. Int J Obes 30, 400-418.

6. Van Gaal LF, Vertommen J \& De Leeuw IH (1998) The in vitro oxidizability of lipoprotein particles in obese and non-obese subjects. Atherosclerosis 137, 39-44.

7. Giudice A, Arra C \& Turco MC (2010) Review of molecular mechanisms involved in the activation of the Nrf2-ARE signaling pathway by chemopreventive agents. Methods Mol Biol 647, 37-74.

8. Thornalley PJ \& Rabbani N (2012) Dietary and synthetic activators of the antistress gene response in treatment of renal disease. J Ren Nutr 22, 195-202.

9. Scalbert A, Manach C, Morand C, et al. (2005) Dietary polyphenols and the prevention of diseases. Crit Rev Food Sci Nutr 45, 287-306.

10. Sinha K, Chaudhary G \& Gupta YK (2002) Protective effect of resveratrol against oxidative stress in middle cerebral artery occlusion model of stroke in rats. Life Sci 71, 655-665.
11. King RE, Bomser JA \& Min DB (2006) Bioactivity of resveratrol. Comp Res Food Sci Food Safety 5, 65-70.

12. López-Vélez M, Martínez-Martínez F \& Valle-Ribes C (2003) The study of phenolic compounds as natural antioxidants in wine. Crit Rev Food Sci Nutr 43, 233-244.

13. Sharma M \& Gupta YK (2002) Chronic treatment with trans-resveratrol prevents intracerebroventricular streptozotocin induced cognitive impairment and oxidative stress in rats. Life Sci 71, 2489-2498.

14. Shigematsu S, Ishida S \& Hara M (2003) Resveratrol, a red wine constituent polyphenol, prevents superoxide-dependent inflammatory responses induced by ischemia/reperfusion, platelet-activating factor, or oxidants. Free Radic Biol Med 34, 810-817.

15. Salem N, Kim HY \& Yergey JA (1985) Health effects of polyunsaturated fatty acids in sea foods. In Docosahexaenoic Acid: Membrane Function and Metabolism, pp. 263-317 [AP Simopoulos, RR Kifer and RE Martin, editors]. Orlando: Academic Press.

16. Siddiqui RA, Harvey KA \& Zaloga GP (2008) Modulation of enzymatic activities by $n-3$ polyunsaturated fatty acids to support cardiovascular health. J Nutr Biochem 19, 417-437.

17. Garrel C, Ceballos-Picot I, Germain G, et al. (2007) Oxidative stress-inducible antioxidant adaptive response during prostaglandin F2alpha-induced luteal cell death in vivo. Free Radic Res 41, 251-259.

18. Zerouga M, Stillwell W, Stone J, et al. (1996) Phospholipid class as a determinant in docosahexaenoic acid's effect on tumor cell viability. Anticancer Res 16, 2863-2868.

19. Stillwell W, Jenski LJ, Crump FT, et al. (1997) Effect of docosahexaenoic acid on mouse mitochondrial membrane properties. Lipids 32, 497-506

20. El-Mowafy AM, Abdel-Dayem MA, Abdel-Aziz A, et al. (2011) Eicosapentaenoic acid ablates valproate-induced liver oxidative stress and cellular derangement without altering its clearance rate: dynamic synergy and therapeutic utility. Biochim Biophys Acta 1811, 460-467.

21. Iraz M, Erdogan H, Ozyurt B, et al. (2005) Omega-3 essential fatty acid supplementation and erythrocyte oxidant/antioxidant status in rats. Ann Clin Lab Sci 35, 169-173.

22. Poderoso JJ, Carreras MC, Lisdero C, et al. (1996) Nitric oxide inhibits electron transfer and increases superoxide radical production in rat heart mitochondria and submitochondrial particles. Arch Biochem Biophys 328, 85-92.

23. Drapper HH \& Hadley M (1990) Malondialdehyde determination as index of lipid peroxidation. Methods Enzymol 186, 421-431.

24. Levine RL, Garland D, Oliver CN, et al. (1990) Determination of carbonyl content in oxidatively modified proteins. Methods Enzymol 186, 464-478.

25. Aebi H (1984) Catalase in vitro. Methods Enzymol 105 121-126.

26. Bannister JV \& Calabrese L (1987) Assays for superoxide dismutase. Methods Biochem Anal 32, 279-312.

27. Flohé L \& Günzler WA (1984) Assays of glutathione peroxidase. Methods Enzymol 105, 114-121.

28. Frederico MJ, Justo SL, Da Luz G, et al. (2009) Exercise training provides cardioprotection via a reduction in reactive oxygen species in rats submitted to myocardial infarction induced by isoproterenol. Free Radic Res 43, 957-964.

29. Rosengren A, Wedel H \& Wilhelmsen L (1999) Body weight and weight gain during adult life in men in relation to coronary heart disease and mortality. A prospective population study. Eur Heart J 20, 269-277. 
30. Ross SJ, Poehlman ET, Johnson RK, et al. (1997) Body fat distribution predicts cardiac risk factors in older female coronary patients. J Cardiopulm Rehabil 17, 419-427.

31. Lakka HM, Lakka TA, Tuomilehto J, et al. (2002) Abdominal obesity is associated with increased risk of acute coronary events in men. Eur Heart J 23, 706-713.

32. Duflou J, Virmani R, Robin I, et al. (1995) Sudden death as a result of heart disease in morbid obesity. Am J Heart 130, 306-313.

33. Nakazono K, Watanabe N, Matsuno K, et al. (1991) Does superoxide underlie the pathogenesis of hypertension? Proc Natl Acad Sci U S A 88, 10045-10048.

34. Furukawa S, Fujita T, Shimabukuro M, et al. (2004) Increased oxidative stress in obesity and its impact on metabolic syndrome. J Clin Invest 114, 1752-1761.

35. Keaney JF, Larson MG, Vasan RS, et al. (2003) Obesity and systemic oxidative stress: clinical correlates of oxidative stress in the Framingham Study. Arterioscler Thromb Vasc Biol 23, 434-439.

36. Zhang H, Zhang J, Ungvari Z, et al. (2009) Resveratrol improves endothelial function role of TNF alpha and vascular oxidative stress. Arterioscler Thromb Vasc Biol 29, $1164-1171$.

37. Gaiva MH, Couto RC, Oyama LM, et al. (2001) Polyunsaturated fatty acid-rich diets: effect on adipose tissue metabolism in rats. Br J Nutr 86, 371-377.

38. Ozata M, Mergen M, Oktenli C, et al. (2002) Increased oxidative stress and hypozincemia in male obesity. Clin Biochem 35, 627-631.

39. Leonard SS, Xia C, Jiang BH, et al. (2003) Resveratrol scavenges reactive oxygen species and effects radical induced cellular responses. Biochem Biophys Res Commun 309, 1017-1026.

40. Robb EL, Page MM, Wiens BE, et al. (2008) Molecular mechanisms of oxidative stress resistance induced by resveratrol: specific and progressive induction of MnSOD. Biochem Biophys Res Commun 367, 406-412.

41. Spanier G, Xu H, Xia N, et al. (2009) Resveratrol reduces endothelial oxidative stress by modulating the gene expression of superoxide dismutase 1 (SOD1), glutathioneperoxidase 1 (GPx1) and NADPH oxidase subunit (Nox4). J Physiol Pharmacol 60, 111-116.

42. McLennan PL \& Abeywardena MY (2005) Membrane basis for fish oil effects on the heart: linking natural hibernators to prevention of human sudden cardiac death. $J \mathrm{Membr}$ Biol 206, 85-102.

43. Barletta MA, Lehr D, Guideri G, et al. (1978) Hemodynamic alterations in isoproterenol-induced cardiac arrhythmias in corticoid-treated rats. J Pharm Sci 67, 1390-1394.

44. Gudbjarnason S (1989) Dynamics of $n-3$ and $n-6$ fatty acids in phospholipids of heart muscle. $J$ Intern Med $\mathbf{7 3 1}$, 117-128.

45. Barbosa DS, Cecchini R, El Kadri MZ, et al. (2003) Decreased oxidative stress in patients with ulcerative colitis supplemented with fish oil omega-3 fatty acids. Nutrition 19 , 837-842.

46. Ashrafian H, Czibik G, Bellahcene M, et al. (2012) Fumarate is cardioprotective via activation of the Nrf2 antioxidant pathway. Cell Metab 15, 361-371.
47. Chen CY, Jang JH, Li MH, et al. (2005) Resveratrol upregulates heme oxygenase-1 expression via activation of NF-E2-related factor 2 in PC12 cells. Biochem Biophys Res Commun 331, 993-1000.

48. Hsieh TC, Lu X, Wang Z, et al. (2006) Induction of quinone reductase NQO1 by resveratrol in human $\mathrm{K} 562$ cells involves the antioxidant response element ARE and is accompanied by nuclear translocation of transcription factor Nrf2. Med Chem Res 2, 275-285.

49. Omata Y, Saito Y, Fujita K, et al. (2008) Induction of adaptive response and enhancement of PC12 cells tolerance by lipopolysaccharide primarily through the upregulation of glutathione $S$-transferase A3 via Nrf2 activation. Free Radic Biol Med 45, 1437-1445.

50. Rubiolo JA, Mithieux G, Vega FV, et al. (2008) Resveratrol protects primary rat hepatocytes against oxidative stress damage: activation of Nrf2 transcription factor and augmented activities of antioxidant enzymes. Eur J Pharmacol 591, $66-72$.

51. Anderson EJ, Thayne K, Harris M, et al. (2012) Aldehyde stress and up-regulation of Nrf2-mediated antioxidant systems accompany functional adaptations in cardiac mitochondria from mice fed $n-3$ polyunsaturated fatty acids. Biochem J 441, 359-366.

52. Ishikado A, Nishio Y, Morino K, et al. (2010) Low concentration of 4-hydroxy hexenal increases heme oxygenase-1 expression through activation of $\mathrm{Nrf} 2$ and antioxidative activity in vascular endothelial cells. Biochem Biophys Res Commun 402, 99-104.

53. Mori TA \& Beilin LJ (2004) Omega-3 fatty acids and inflammation. Curr Atheroscler Rep 6, 461-467.

54. Tsai SH, Lin-Shiau SY \& Lin JK (1999) Suppression of nitric oxide synthase and the down-regulation of the activation of NFkappaB in macrophages by resveratrol. BrJ Pharmacol 126, 673-680.

55. Manna SK, Mukhopadhyay A \& Aggarwal BB (2000) Resveratrol suppresses TNF-induced activation of nuclear transcription factors NF-kappa B, activator protein-1, and apoptosis: potential role of reactive oxygen intermediates and lipid peroxidation. J Immunol 164, 6509-6519.

56. Rodrigo R, Prieto JC \& Castillo R (2013) Cardioprotection against ischaemia/reperfusion by vitamins $\mathrm{C}$ and $\mathrm{E}$ plus $n-3$ fatty acids: molecular mechanisms and potential clinical applications. Clin Sci (Lond) 124, 1-15.

57. Pallarès V, Calay D, Cedó L, et al. (2012) Enhanced anti-inflammatory effect of resveratrol and EPA in treated endotoxin-activated RAW 264.7 macrophages. $\mathrm{Br}$ J Nutr 108, 1562-1573.

58. Kaneko H, Anzai T, Morisawa M, et al. (2011) Resveratrol prevents the development of abdominal aortic aneurysm through attenuation of inflammation, oxidative stress, and neovascularization. Atherosclerosis 217, 350-357.

59. Zang QS, Sadek H, Maass DL, et al. (2012) Specific inhibition of mitochondrial oxidative stress suppresses inflammation and improves cardiac function in a rat pneumonia-related sepsis model. Am J Physiol Heart Circ Physiol 302, H1847-H1859. 